\title{
Alain-Jacques CZOUZ-TORNARE, La Révolution française pour les nuls
}

Paul Chopelin

\section{(2) OpenEdition \\ 1 Journals}

Édition électronique

URL : https://journals.openedition.org/ahrf/11736

DOI : 10.4000/ahrf.11736

ISSN : 1952-403X

Éditeur :

Armand Colin, Société des études robespierristes

\section{Édition imprimée}

Date de publication : 1 septembre 2010

Pagination : 201

ISBN : 978-2-200-92633-5

ISSN : 0003-4436

Référence électronique

Paul Chopelin, «Alain-Jacques czouz-tornare, La Révolution française pour les nuls », Annales historiques de la Révolution française [En ligne], 361 | juillet-septembre 2010, mis en ligne le 22 mars 2011, consulté le 23 avril 2022. URL : http://journals.openedition.org/ahrf/11736 ; DOl : https:// doi.org/10.4000/ahrf.11736

Ce document a été généré automatiquement le 23 avril 2022.

Tous droits réservés 


\title{
Alain-Jacques CZOUZ-TORNARE, La Révolution française pour les nuls
}

\author{
Paul Chopelin
}

\section{RÉFÉRENCE}

Alain-Jacques Czouz-Tornare, La Révolution française pour les nuls, Paris, First

Editions, coll. « Pour les nuls », 2009, 420 p., ISBN 978-2-7540-0811-2, $22.90 €$.

1 Créée aux États-Unis au début des années 1990 et destinée aux débutants en informatique, la collection « Pour les nuls » aborde désormais des domaines très divers, de la cuisine au marketing, en passant par le bricolage et la puériculture. L'objectif est de rendre accessibles au plus grand nombre les connaissances de base sur un sujet donné, en utilisant un style toujours alerte, qui cherche à soutenir l'attention du lecteur profane par l'usage de calembours, de jeux de mots et de comparaisons décalées : "rire tout en apprenant ", tel est le slogan affiché sur le site internet de la collection. La formule a rencontré un grand succès public, devenant une véritable référence collective, même si des critiques ont pu être récemment émises sur les faiblesses et le parti pris de certains titres de sciences humaines (Gaël BRUSTIER, «Ce que parler aux 'nuls' veut dire ", dans Le Monde diplomatique, octobre 2009, p. 28). Depuis 2004, la série « Pour les nuls » s'est enrichie de volumes historiques, qui ont suscité un véritable engouement : 800000 exemplaires de L'Histoire de France pour les nuls auraient ainsi été vendus depuis cinq ans. En 2009, c'est au tour de la Révolution française d'être expliquée aux « nuls », par l'intermédiaire d'Alain-Jacques Czouz-Tornare.

2 L'ouvrage remplit-il ses objectifs ? Sur le style, rien à dire : légèreté de ton et jeux de mots - il y en a pour tous les goûts - sont au rendez-vous, contribuant effectivement à ôter tout ennui à la lecture de ce gros volume de 420 pages. Sur le fond, l'impression est plus mitigée. Après une profession de foi d'objectivité («nous vous offrons ici une vision globale et équitable de la Révolution française», p. 3), Alain-Jacques CzouzTornare affirme que «n'ont manqué à la Révolution ni le crime ni la poésie. Et chacun y 
trouvera son compte, à défaut de le régler " (p. 9). Chacun peut y trouver son compte certes et s'il y a bien équilibre entre les interprétations, ce qui est fort louable, force est de constater qu'il s'agit souvent d'un équilibre dans la caricature. Ainsi, on n'évitera pas dans les deux premiers chapitres, la traditionnelle appréciation - qu'il aurait été facile de bousculer un peu - sur les philosophes " pères spirituels de la Révolution » et sur les «bêtises » de Louis XVI. La quatrième partie, consacrée aux années 1792-1794, offre au lecteur un véritable florilège de clichés sur la Terreur. Dans l'introduction de cette partie, l'auteur explique que «les comités de surveillances révolutionnaires règnent en maîtres et font peser la terreur sur le pays afin d'y rétablir l'ordre républicain quoi qu'il en coûte » (p. 204). Plus loin, on apprend que « la Convention n'en continue pas moins de légiférer tous azimuts, mariant à tour de bras la carpe démocratique avec le lapin libéral »(p. 223). Les informations ne sont pas toujours vérifiées : selon l'auteur, «six mille Lyonnais sont égorgés et déchiquetés » (p. 234) lors de la répression de l'insurrection de 1793, alors que le nombre exact des victimes, connu depuis longtemps, est de 1865 personnes fusillées ou décapitées (même remarque pour les chiffres des victimes lyonnaises de la réaction thermidorienne, p. 292). En revanche, pas un mot sur les représentants en mission, leur rôle exact et les images fantasmatiques qu'ils ont pu susciter depuis 1794.

3 Mais que les révolutionnaires se rassurent, il y en a autant pour l'autre camp: le cardinal de Rohan devient ainsi « un dépravé pas très catholique » (p. 37), « la famille Bourbon, à force de consanguinité, est alors ce qu'on appelle une fin de race » (p. 300), tandis que les compagnons de Jésus se livrent à Lyon à « des chasses à l'homme aux airs de pogromes» (p. 292). Par un raccourci pour le moins surprenant, l'auteur va même jusqu'à renvoyer dos à dos catholiques sanguinaires et révolutionnaires enragés, issus, selon lui, du même creuset : «La Révolution est d'ailleurs, à l'origine, profondément marquée par l'héritage catholique. Elle reprend l'idée de l'Inquisition de retirer la qualité d'hommes à ceux qui gênent et d'en finir avec eux» (p. 248). Quelques pages après (p. 267), le lecteur apprend en effet comment, pendant la Terreur, le totalitarisme républicain a succédé au totalitarisme catholique! Plus globalement, les passages concernant les questions religieuses contiennent beaucoup d'affirmations erronées, notamment sur l'attitude du clergé catholique et de ses fidèles à l'égard de la Révolution. Enfin, le souci d'équilibre n'est pas toujours respecté dans la structure même de l'ouvrage: les contre-révolutionnaires auraient quand même pu avoir leur place parmi les dix lieux de mémoire sélectionnés en annexe, tandis que Le réveil du Peuple aurait mérité de figurer parmi les dix chansons phares de la période !

4 En dépit de ces simplifications abusives, cet ouvrage possède des qualités indéniables. L'auteur apporte en effet des jugements nuancés sur des événements (les guerres de Vendée) et des périodes (le Directoire) souvent caricaturées par ailleurs, notamment dans les manuels scolaires. Le déroulement chronologique est clairement exposé et l'auteur n'oublie pas d'évoquer, dans un dernier chapitre, l'Empire et la Restauration pour mesurer l'héritage politique immédiat de la Révolution. On peut dire ainsi que le pari éditorial est globalement gagné : offrir une synthèse claire et accessible à tous sur une suite d'événements particulièrement complexes. Il est seulement regrettable, je le répète, que l'abus de formules lapidaires contribue à entretenir les habituelles légendes - noires ou roses - de la Révolution. Mais à une époque où le livre d'histoire a quitté depuis bien longtemps le rayon des best-seller et où la télévision propose des fictions calamiteuses sur la période, il faut malgré tout remercier A.-J. Czouz-Tornare d'avoir 
mené à bien cette œuvre de vulgarisation iconoclaste et jamais ennuyeuse, qui, espérons-le, pourra réveiller la curiosité du grand public pour la Révolution. 